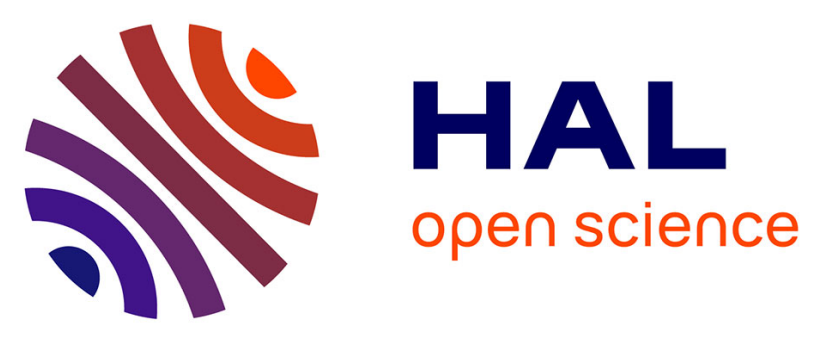

\title{
Application of Doehlert Matrix for an Optimized Preparation of a Surface-Enhanced Raman Spectroscopy (SERS) Substrate Based on Silicon Nanowires for Ultrasensitive Detection of Rhodamine 6G
}

Awatef Ouhibi, Maroua Saadaoui, Nathalie Lorrain, Mohammed Guendouz, Noureddine Raouafi, Adel Moadhen

\section{To cite this version:}

Awatef Ouhibi, Maroua Saadaoui, Nathalie Lorrain, Mohammed Guendouz, Noureddine Raouafi, et al.. Application of Doehlert Matrix for an Optimized Preparation of a Surface-Enhanced Raman Spectroscopy (SERS) Substrate Based on Silicon Nanowires for Ultrasensitive Detection of Rhodamine 6G. Applied Spectroscopy, 2020, 74 (2), pp.168-177. 10.1177/0003702819881222 . hal-02400250

\author{
HAL Id: hal-02400250 \\ https://hal.science/hal-02400250
}

Submitted on 9 Dec 2019

HAL is a multi-disciplinary open access archive for the deposit and dissemination of scientific research documents, whether they are published or not. The documents may come from teaching and research institutions in France or abroad, or from public or private research centers.
L'archive ouverte pluridisciplinaire HAL, est destinée au dépôt et à la diffusion de documents scientifiques de niveau recherche, publiés ou non, émanant des établissements d'enseignement et de recherche français ou étrangers, des laboratoires publics ou privés. 
DOI: $10.1177 / 0003702819881222$

\title{
Application of Doehlert Matrix for an Optimized Preparation of a Surface-Enhanced Raman Spectroscopy (SERS) Substrate Based on Silicon Nanowires for Ultrasensitive Detection of Rhodamine 6G
}

Awatef Ouhibi ${ }^{\mathrm{a}}$, Maroua Saadaoui ${ }^{\mathrm{b}}$, Nathalie Lorrain ${ }^{\mathrm{c}}$, Mohammed Guendouz ${ }^{\mathrm{c}}$, Noureddine Raouafi ${ }^{\mathrm{b}}$ and Adel Moadhen ${ }^{\mathrm{a}^{* *}}$

${ }^{a}$ Université de Tunis El Manar, Faculté des Sciences de Tunis, Unité des Nanomateriaux et Photonique (13ES31), 2092, Tunis El Manar, Tunisie

${ }^{\mathrm{b}}$ Université de Tunis El Manar, Faculté des Sciences de Tunis, Laboratoire de Chimie Analytique et Electrochimie (LR99ES15), Sensors and Biosensors Group, 2092, Tunis El Manar, Tunisie

${ }^{c}$ Université de Rennes, CNRS, Institut Foton, UMR 6082, F-22305, Lannion, France

Corresponding authors:* nathalie.lorrain@univ-rennes1.fr, ** adel.moadhen@istmt.utm.tn

\begin{abstract}
In this work, we combined a hierarchical nano-array effect of silicon nanowires (SiNWs) with a metallic surface of silver nanoparticles (AgNPs) to design a surface-enhanced Raman spectroscopy (SERS) scattering substrate for sensitive detection of Rhodamine 6G (R6G) which is a typical dye for fluorescence probes. The SiNWs were prepared by Metal-Assisted Chemical Etching (MACE) of n-Si (100) wafers. The Doehlert design methodology was used for planning the experiment and analyzing the experimental results. Thanks to this methodology, the R6G SERS response has been optimized by studying the effects of the silver nitrate concentration, silver nitrate and R6G immersion times and their interactions. The immersion time in R6G solution stands out as the most of influential factor on the SERS response.

Keywords: Silicon nanowires, silver nanoparticles, surface-enhanced Raman spectroscopy substrate, SERS substrate, Doehlert matrix, detection

\section{Introduction}

Fast results analysis, cost-effectiveness, and simultaneous study of several parameters are the main requirements for analytical methodologies optimization and development. Surfaceenhanced Raman spectroscopy (SERS) is well recognized as a powerful tool to analyze chemical and biological samples due to the wealth of information it provides from the vibrational
\end{abstract}


DOI: $10.1177 / 0003702819881222$

fingerprinting of molecules. ${ }^{1}$ SERS effect takes place when the target is adsorbed on the metal surface. ${ }^{1,2}$ Using optimal parameters, Raman signals can be increased by up to fifteen orders of magnitude to ensure the ability to detect very low concentration of molecules, or even the detection of a single molecule. . $^{3,4}$

Electromagnetic and chemical effects are recognized as the most contributing factors to Raman signal enhancement. ${ }^{1}$ These effects are respectively due to the increase of electromagnetic fields by the resonant excitation of the plasmon surface via the photon interaction and to the charge-transfer gaps between adsorbed target and metal. ${ }^{5,6}$ Silver and gold nanoparticles are the two most often used SERS substrates due to their outstanding optical properties, their high enhancement factors and their low reactivity.

The large surface-to-volume ratio and the one-dimensional structure of silicon nanowires (SiNWs) dramatically modify the electrical and optical properties of the bulk silicon, ${ }^{7-11}$ which makes them suitable candidates for numerous applications such as diagnosis of diseases, ${ }^{12}$ sensing, ${ }^{13-15}$ catalysis,${ }^{16}$ manufacture of batteries, ${ }^{17}$ and micro-super capacitors and solar cells. ${ }^{18,19}$

Over the past two decades, many strategies have been developed to combine a hierarchical nano-array effect of silicon nanowires decorated with a metallic surface of silver nanoparticles (AgNPs) in order to design high-performance SERS substrates. ${ }^{20-22}$ The optimization of SERS substrates by the traditional univariate approach wherein only one parameter is changed while the others are fixed requires ongoing testing and much time for results interpretation. Moreover, this traditional method is less effective. For these reasons, the choice of the univariate approach for optimization and development of analytical methodologies is being replaced by multivariate approaches for their advantages of identifying the different intertwining of variables, avoiding time-consuming experiments and obtaining an efficient data analysis. $^{23}$

In this work, we combine the effect of an etched surface area of silicon with the surface Plasmon of AgNPs to optimize SERS substrate preparation for ultrasensitive detection of Rhodamine 6G (R6G) by varying silver nitrate concentration, silver nitrate and R6G immersion times. The interdependence of these different parameters dictated the use of a multivariate method allowing simultaneous modification of the mentioned above three parameters. 
DOI: $10.1177 / 0003702819881222$

The Doehlert plan was used first to plan the experiment, then to determine the optimal conditions by studying the effect of the experimental parameters on the R6G SERS response and the interactions between them. ${ }^{24-27}$

\section{Experimental}

\section{Reagents and Materials}

Silver nitrate, hydrofluoric acid (40\%), hydrogen peroxide (34\%), nitric acid (70\%), sulfuric acid (97\%), and Rhodamine 6G from Sigma-Aldrich (Germany) were used for all the experiments. All solutions were prepared using ultrapure water produced by a Millipore system.

The morphological properties of the as obtained SiNWs and AgNPs/SiNWs surface were studied by scanning electron microscopy (SEM) using HITACHI SU3500 microscope. The SERS measurements were performed at room temperature (RT) on a Micro Raman HORIBA system (LabRAM HR800). A helium-neon laser with a power of about $1 \mathrm{~mW}$ was used for excitation at $632.8 \mathrm{~nm}$ of the sample surface. Data were collected with an integration time of ten seconds.

The construction of the design experimental methodology, the modeling of the SERS responses and the drawing of the various representations were carried out using NemrodW software (v.2000, LPRAI, France).

\section{Elaboration of SERS Substrates}

The SiNWs were prepared using metal-assisted chemical etching (MACE) of n-Si (100) wafers. ${ }^{28}$ Briefly, wafers with a surface of $1 \mathrm{~cm}^{2}$ were cleaned in a acetone and ethanol solution for 15 minutes. Then, they were immersed into a solution of $\mathrm{H}_{2} \mathrm{O}_{2}$ and $\mathrm{H}_{2} \mathrm{SO}_{4}$ in a ratio 1:3 [v/v] for 10 minutes. After that, the wafers were immersed in a 5\% $\mathrm{HF}$ aqueous solution for three minutes to obtain $\mathrm{H}$-terminated silicon surfaces. The wafers were immediately immersed in a aqueous solution containing $5.10^{-3} \mathrm{M}$ of $\mathrm{Ag} \mathrm{NO}_{3}$ and $4.8 \mathrm{M}$ of $\mathrm{HF}$ for one minute in order to form AgNPs before being thoroughly washed with ultrapure water. Subsequently, the as obtained samples were immersed in an aqueous etching solution composed of $4.8 \mathrm{M} \mathrm{HF}$ and $0.4 \mathrm{M} \mathrm{H}_{2} \mathrm{O}_{2}$ for 45 minutes to prepare SiNWs. Moreover the samples were immersed in aqueous solution of $\mathrm{HNO}_{3}$ for one hour to remove the Ag catalyst. Finally, they were rinsed with ultrapure water and dried at room temperature. 
DOI: $10.1177 / 0003702819881222$

The AgNPs were deposited on the SiNWs samples through chemical bath immersion in an aqueous solution containing $\mathrm{Ag} \mathrm{NO}_{3}$ and $\mathrm{HF}^{29}$ The SERS substrates were immersed in $10^{-6} \mathrm{M}$ of R6G solution. The samples were rinsed after each immersion step using ultrapure water and they were dried at room temperature.

\section{Experimentation Using the Doehlert Design}

The response of the SERS substrate based on SiNWs is influenced by several experimental conditions. We present here the optimization of AgNPs-SiNWs elaboration by varying silver nitrate concentration, immersion time in silver nitrate solution and R6G solution using the multivariate method to improve the SERS response. This method is interesting because it enables to simultaneously evaluate the effect of the three chosen factors (silver nitrate concentration, immersion times in silver nitrate and R6G solution) on the SERS response and to examine their interaction as well as to determine the optimal conditions. ${ }^{30}$ The as-adopted method is based on statistical tools to limit the number of experiments in selected experimental field. ${ }^{31}$ In our case, Doehlert matrix was chosen as the most adequate multivariate systems because the experimental points are uniformly distributed in the studied field. Furthermore, it allows adding new experimental points without changing the matrix and minimizing the number of experimental points. For a number of factors $k$, the number of experiments is $k^{2}+k+1+n_{0}$, where $n_{0}$ is the number of experiments repetition of the center point. ${ }^{24}$ Using the three factors mentioned above, the number of Doehlert experiment is 13 without the experiment repetition as can be observed in Figure $1 .{ }^{32}$ Silver nitrate concentration has five levels, silver nitrate time has seven levels and R6G time has three levels. Taking into account two additional experiments at the center, the designed experimental methodology is then composed of fifteen experiments presented in Table I with the experimental values of the studied factors $U_{1}, U_{2}, U_{3}$, which represent respectively the silver concentration in $\mathrm{M}$, the immersion time in silver nitrate in second, the immersion time in RG6 in minute. All experiments were conducted in a random order to avoid any tendency in the measurements. ${ }^{33}$

To evaluate the influence of the operating parameters and the interaction between them on the experimental SERS response, coded variables were used.

The transformation of real variable (Ui) into coded variable (Xi) is made using the following equation. 
DOI: $10.1177 / 0003702819881222$

$\mathrm{X}_{i}=\left(\mathrm{U}_{i}-\mathrm{U}_{\mathrm{i} 0}\right) / \Delta u_{i}$

where $\mathrm{X}_{\mathrm{i}}$ is the coded variable $i, U_{i}$ is the real variable $i, \mathrm{U}_{i 0}$ is the value of the real variable $i$ in the center, and $\Delta \mathrm{u}_{i}$ is the range of variation of the real variable $i$.

The investigated experimented domain of the studied factors $U i$ are summarized in Table II.

For three variables, the experimental response associated by a Doehlert matrix was represented by a quadratic polynominal model Y:

$Y=b_{0}+b_{1} X_{1}+b_{2} X_{2}+b_{3} X_{3}+b_{11} X_{1}^{2}+b_{22} X_{2}^{2}+b_{33} X_{2}^{2}+b_{12} X_{1} X_{2}+b_{13} X_{1} X_{3}+b_{23} X_{2} X_{3}$

with $b_{i}$ as the principal estimation of the effect of factor $\mathrm{Ui}$ on the exprimental response, $b_{i i}$ as the second estimation of the effect of factor $\mathrm{Ui}$ on the exprimental response, $b_{\mathrm{ij}}$ as the estimation of the effect of the interaction between the factor $\mathrm{Ui}$ and the factor $\mathrm{Uj}$.

The calculation of the coefficients b (bi, bii or bij) was obtained using the least squares method:

$\mathrm{b}=\left(\mathrm{X}^{\mathrm{T}} \mathrm{X}\right)^{-1} \mathrm{X}^{\mathrm{T}} \mathrm{Y}$

where $\mathrm{Y}$ is the vector of experimental response, $\mathrm{X}$ is the model matrix, and $\mathrm{X}^{\mathrm{T}}$ is the transposed model matrix.

\section{Results and Discussion}

Morphology of SiNWs and AgNPs/SiNWs

Figure 2a shows SEM images of SiNWs prepared using metal-assisted chemical etching (MACE). The SiNWs cross sectional image presented in Figure 2a indicates an identical large area of nanowires having a one-dimensional structure. They are distinguishable and the majority of them are vertical with regard to the sample surface. The layer thickness of the nanostructure is about $20 \mu \mathrm{m}$. The synthesized AgNPs have a spherical shape as it can be seen in Figure $2 \mathrm{~b}$, which present a scanning electron microscopy (SEM) image of the surface AgNPs/SiNWs. The nanoparticles are well dispersed on the SiNWs surface with a non-uniform particle size in the range around of $40-120 \mathrm{~nm}$. 
DOI: $10.1177 / 0003702819881222$

\section{Surface-Enhanced Raman Scattering Effect}

Figure 3 displays three Raman spectra corresponding to (a) SiNWs, (b) R6G $\left(10^{-6} \mathrm{M}\right) / \mathrm{SiNWs}$, and (c) R6G $\left(10^{-6} \mathrm{M}\right) / \mathrm{AgNPs} / \mathrm{SiNW}$. The Raman spectrum of SiNWs only includes the vibrational modes of silicon, whereas the two R6G spectra show other vibrational modes; however, the intensities of Raman peaks in the spectrum of $\mathrm{R} 6 \mathrm{G}\left(10^{-6} \mathrm{M}\right) / \mathrm{SiNW}$ are negligible compared to those of SERS peaks in the R6G $\left(10^{-6} \mathrm{M}\right) / \mathrm{AgNPs} / \mathrm{SiNW}$ spectrum. These modes are in agreement with the R6G vibration modes defined by Hildbrand in $1984 .{ }^{34,35}$ We present here some of the strongest R6G vibration modes: The mode at $610 \mathrm{~cm}^{-1}$ ( noted $\mathrm{L}_{1}$ ) is attributed to $\mathrm{C}$ $\mathrm{C}-\mathrm{C}$ ring in-plane bending mode, the modes at $1360 \mathrm{~cm}^{-1}$ ( noted $\mathrm{L}_{2}$ ), $1509 \mathrm{~cm}^{-1}$ ( noted $\mathrm{L}_{3}$ ), and $1650 \mathrm{~cm}^{-1}$ ( noted $\left.\mathrm{L}_{4}\right)$ are attributed to aromatic $\mathrm{C}-\mathrm{C}$ stretching modes. $\mathrm{L}_{\mathrm{Si}}$ correspond to silicon mode at $520 \mathrm{~cm}^{-1}$. The appearance of a strong R6G SERS signal after the addition of the silver nanoparticles clearly demonstrates the theoretical approach regarding Raman signals enhancement via the resonant excitation of the surface Plasmon by photon interaction.

The SERS effect mainly arises from the nanostructure Plasmon resonance, it is typically wavelength dependent. In order to optimize the wavelength excitation, the R6G SERS substrate (R6G $\left.\left(10^{-6} \mathrm{M}\right) / \mathrm{AgNPs} / \mathrm{SiNWs}\right)$ was excited by two excitation wavelengths which are $488 \mathrm{~nm}$ and $632.8 \mathrm{~nm}$. Figure 4 shows that the majority of R6G vibration modes of the substrate excited at $632.8 \mathrm{~nm}$ are more enhanced than those of the substrate excited at $488 \mathrm{~nm}$. For this reason, we have completed the work by the excitation wavelength $632.8 \mathrm{~nm}$.

\section{Optimization of SERS Substrate Elaboration Using the Doehlert Matrix}

After the elaboration of the fifteen experiments previously presented in Figure 1, Table I, and Table II, the samples were characterized using Raman spectroscopy. Figure 5 shows the evolution of the four R6G vibrational modes at $610 \mathrm{~cm}^{-1}\left(\mathrm{~L}_{1}\right), 1360 \mathrm{~cm}^{-1}\left(\mathrm{~L}_{2}\right), 1509 \mathrm{~cm}^{-1}\left(\mathrm{~L}_{3}\right)$, and $1650 \mathrm{~cm}^{-1}\left(\mathrm{~L}_{4}\right)$ normalized by the silicon mode at $520 \mathrm{~cm}^{-1}\left(\mathrm{~L}_{\mathrm{Si}}\right)$ for the fifteen samples. These normalized modes are respectively noted $\left(\mathrm{L}_{1} / \mathrm{L}_{S i}\right),\left(\mathrm{L}_{2} / \mathrm{LSi}_{\mathrm{Si}}\right),\left(\mathrm{L}_{3} / \mathrm{L}_{\mathrm{Si}}\right)$ and $\left(\mathrm{L}_{4} / \mathrm{L}_{\mathrm{Si}}\right)$.

According to Figure 5, we can conclude that the four Raman vibrational modes of the fifteen samples have the same evolution. In addition, the most intense R6G peak is located at $1360 \mathrm{~cm}^{-1}\left(\mathrm{~L}_{2} / \mathrm{LSi}_{\mathrm{Si}}\right)$. Therefore, $\mathrm{L}_{2} / \mathrm{L}_{\mathrm{Si}}$ was chosen in the Doehlert model in order to follow the evolution of the SERS response by varying the three parameters. In addition, Figure 5 clearly 
DOI: $10.1177 / 0003702819881222$

shows that the Raman enhancement is optimal for both samples $\mathrm{N}^{\circ} 2$ and $\mathrm{N}^{\circ} 15$ (rand) of the experimental design methodology (Table I).

The effects of silver nitrate concentration as well as immersion times in silver nitrate and R6G solution on SERS response were investigated using Doehlert matrix.

Taking into consideration the experimental results previously presented, the rate $\mathrm{L}_{2} / \mathrm{L}_{\mathrm{Si}}$ were introduced for all the fifteen samples in Nemrod software, as well as the the data defined in Table I. Then, the coefficients b (bi, bii, bij) of the polynominal model defined in Eq. 2 were determined by the treatement of all the data. They are presented in the following equation $\mathrm{Y}=0.067+0.024 \mathrm{X}_{1}-0.021 \mathrm{X}_{2}+0.16 \mathrm{X}_{3}+0.048 \mathrm{X}_{1}^{2}+0.092 \mathrm{X}_{2}^{2}+0.16 \mathrm{X}_{3}^{2}+0.017$ $\mathrm{X}_{1} \mathrm{X}_{2}-0.12 \mathrm{X}_{1} \mathrm{X}_{2}-0.048 \mathrm{X}_{1} \mathrm{X}_{3}$

The obtained coefficients are also presented in graphical form in Figure 6 in order to visualize easily the estimation of $b_{i}$ and $b_{i i}$ coefficients, respectively corresponding to the principal and the second effect of the factor $U_{i}$ on the experimental response, as well as the estimation of $b_{i j}$ coefficients corresponding to the interaction effect between the factor $U_{i}$ and the factor $U_{j}$.

The coefficient $b_{1}$ provides information on the effect of silver nitrate concentration, whereas $b_{2}$ and $b_{3}$ provide information on immersion time respectively in silver nitrate and R6G solution.

The coefficients presented in the Figure 6 well show that the main influencing parameter on the studied response is the R6G immersion time $\left(b_{3}\right.$ is greater than $b_{1}$ and $\left.b_{2}\right)$. Silver nitrate concentration and the R6G immersion time have positive estimation effects on the experimental response (since $b_{1}$ and $b_{3}$ are positive). Thus, an increase on the both parameters leads to the augmentation of the observed response. However, an increase in silver nitrate incubation time decreases the response (since $b_{2}$ is negative). The $b_{12}$ coefficient, which corresponds to the interaction between the silver nitrate concentration and the silver nitrate immersion time, is positive as noted in Figure 6. Thus, there is an interaction between both parameters. ${ }^{26,36}$

To properly interpret the results of the parameter study, the predicted contour plots and their corresponding three-dimensional representations are given in the Figures 6e to $7 \mathrm{a}$. The zone characterized by a maximal SERS response overall the three-dimensional representations is in red as it can be seen in the various representations. 
DOI: $10.1177 / 0003702819881222$

A $\mathrm{AgNO}_{3}$ concentration equals $5 \mathrm{mM}$, Figures $6 \mathrm{~b}$ and $7 \mathrm{a}$ depict the contour plots and their corresponding three-dimensional representations showing the SERS response with regard to the silver nitrate and R6G immersion time. Both indicate that the maximal SERS response is obtained by increasing the R6G immersion time to above 38-40 minutes. The contours are exhibited by circles centered around the middle of the studied field of silver nitrate immersion time denoting a maximal SERS response located in the middle of this field.

For a silver nitrate immersion time of 67-68 seconds, Figures $6 \mathrm{~d}$ and $7 \mathrm{c}$ depict the contour plots and their corresponding three-dimensional representations showing the SERS response with respect to silver nitrate concentration and immersion time in R6G solutions. Accordingly, we can conclude that the maximum response is obtained by increasing R6G immersion time.

Figures 7c and d also indicate the SERS response is enhanced by increasing silver nitrate concentration from above 5-7 $\mathrm{mM}$. Moreover, the Raman response seems to be more sensitive to the variation of R6G immersion time than the variation of the silver nitrate concentration. This could be explained by a longer immersion time which would enable the adsorption of R6G molecules in organized manner on the silver nanoparticle surface.

For an R6G immersion time of 38 minutes, the contour plots and their corresponding three-dimensional are displayed in Figures 7e and $\mathrm{f}$.

An analysis of these figures shows that the response is maximal for a broad area of silver nitrate concentration and silver nitrate immersion time. The contour plots confirm also the interaction between both parameters.

Consequently, to obtain a maximized SERS response, the SiNWs must be immersed in a silver nitrate concentration ranging from 5 to $7 \mathrm{mM}$ during 67 to 68 seconds, followed by R6G solution immersion for more than 38 minutes.

\section{Limit of Detection and Enhancement Factor}

The limit of detection (LOD) is recognized as one of the main parameters to characterize a given sensing platform. It informs about the lowest target concentration to be detected by the platform. Based on the optimal conditions obtained by the previously work, Figure 8 presents the SERS spectra of the optimized AgNPs/SiNWs substrates (Sample 2 of the experimental design) soaked in R6G solutions of different concentrations ranging from (b) $10^{-11} \mathrm{M}$ to (e) $10^{-6} \mathrm{M}$. As noted, 
DOI: $10.1177 / 0003702819881222$

the most R6G vibration modes are visible at the R6G SERS spectra of the different concentrations greater than $10^{-11} \mathrm{M}$. The most prominent modes located at $610 \mathrm{~cm}^{-1}, 779 \mathrm{~cm}^{-1}$, $1509 \mathrm{~cm}^{-1}, 1570 \mathrm{~cm}^{-1}$, and $1650 \mathrm{~cm}^{-1}$ have undergone a decrease in their scattered intensity when the R6G concentration varies from $10^{-6}$ to $10^{-11} \mathrm{M}$. We can conclude that the limit of detection is about $10^{-11} \mathrm{M}$.

Enhancement factor $(\mathrm{EF})$ is also a very important parameter to demonstrate the effectiveness of SERS. In this framework, we estimate the EF by the following equation, which was used by Ngan et al.: ${ }^{37}$

$$
\mathrm{EF}=\frac{\mathrm{I}_{\mathrm{SERS}} / \mathrm{N}_{\text {Raman }}}{\mathrm{I}_{\text {Raman }} / \mathrm{N}_{\text {SERS }}}
$$

where $I_{S E R S}$ and $I_{\text {Raman }}$ are the Raman intensity of a diagnostic band of the probe molecules adsorbed on the SERS and non-SERS substrate, respectively. $\mathrm{N}_{\text {SERS }}$ is the number of molecules on the SERS substrate and $\mathrm{N}_{\text {Raman }}$ is the number of molecules on the non-SERS substrate, which caused respectively ISERS and IRaman. To estimate the EF of the SERS substrate, the SERS spectrum of R6G at a concentration of $10^{-10} \mathrm{M}\left(\mathrm{R} 6 \mathrm{G}\left(10^{-10}\right) / \mathrm{AgNPs} / \mathrm{SiNWs}\right)$ and a Raman spectrum of R6G at a concentration of $10^{-6} \mathrm{M}\left(\mathrm{R} 6 \mathrm{G}\left(10^{-6}\right) / \mathrm{SiNWs}\right)$ were used. The Raman band at $1360 \mathrm{~cm}^{-1}\left(\mathrm{~L}_{2}\right)$ has been chosen to calculate the EF.

With the assumption that R6G solution is evenly distributed on the surface of the sample, the ratio $\mathrm{N}_{\text {SERS }} / \mathrm{N}_{\text {Raman }}$ is considered as equal to the ratio of the $\mathrm{R} 6 \mathrm{G}$ concentrations in which the non-SERS and the SERS substrates were incubated, respectively. The SERS intensity at $1360 \mathrm{~nm}$ is equal to 1600 and the Raman intensity is equal to 29 . The EF estimated to $0.610^{6}$.

\section{Conclusion}

In this study, an enlarged surface area of vertically aligned silicon nanowires decorated with silver nanoparticles was used in order to build SERS substrates capable of detecting a remarkably lower R6G concentration under optimal conditions. The Doehlert design was adopted in order to estimate the effects of the studied parameters on the R6G SERS response and to obtain the optimal conditions for SERS substrates development. The multivariate method showed that the R6G immersion time was the main influential factor to the response. In addition, an interaction between the silver nitrate concentration and silver nitrate immersion time was found. An optimal SERS response can be achieved by immersion the SiNWs in 5 to $7 \mathrm{mM}$ 
DOI: $10.1177 / 0003702819881222$

nitrate silver concentrations during 67-68 seconds followed by R6G solution immersion for more than 38 minutes. The sensing platform characterized by a limit of detection about $10^{-11} \mathrm{M}$ and an enhancement factor estimated to $0.610^{6}$.

\section{Acknowledgments}

The authors acknowledge the financial support from the University of Tunis El Manar for the mobility grant (Bourse d'alternance) awarded to Awatef Ouhibi.

\section{References}

1. E. Ru, P. Etchegoin. "Principles of Surface-Enhanced Raman Spectroscopy and Related Plasmonic Effects". Amsterdam: Elsevier, 2009.

2. M. Fleischmann, P.J. Hendra, A.J. McQuillan. "Raman Spectra of Pyridine Adsorbed at a Silver Electrode". Chem. Phys. Lett. 1974. 26(2): 163-166.

3. M.G. Albrecht, J.A. Creighton. "Anomalously Intense Raman Spectra of Pyridine at a Silver Electrode". Am. Chem. Soc. 1977. 99(15): 5215-5217.

4. D.L. Jeanmaire, R.P. Van Duyne. "Blu Excited State of the Tetracyanoquinodimethane Anion Radical”. J. Electroanal. Chem. 1977. 84: 1-20.

5. J. Wang, W. Lin, E. Cao, X. Xu, et al. "Surface Plasmon Resonance Sensors on Raman and Fluorescence Spectroscopy". Sensors. 2017. 17(12): 2719-2738.

6. S. Zou, G.C. Schatz. "Silver Nanoparticle Array Structures that Produce Giant Enhancements in Electromagnetic Fields". Chem. Phys. Lett. 2005. 40(1-3): 62-67.

7. S. Li, W. Ma, X. Chen, K. Xie, et al. "Structure and Antireflection Properties of SiNWs Arrays Form mc-Si Wafer Through Ag-Catalyzed Chemical Etching”. Appl. Surf. Sci. 2016. 369: 232-240.

8. C. Zhang, S. Li, W. Ma, Z. Ding, et al. "Fabrication of Ultra-Low Antireflection SiNWs Arrays from mc-Si Using One Step MACE”. J. Mater. Sci. Mater. Electron. 2017. 28(12): $8510-8518$.

9. H. Han, Z. Huang, W. Lee. "Metal-Assisted Chemical Etching of Silicon and Nanotechnology Applications". Nano Today. 2014. 9(3): 271-304. 
DOI: $10.1177 / 0003702819881222$

10. K.A. Gonchar, A.A. Zubairova, A. Schleusener, L.A. Osminkina, et al. "Optical Properties of Silicon Nanowires Fabricated by Environment-Friendly Chemistry". Nanoscale Res. Lett. 2016. 11(1): 357-362.

11. S.D. Hutagalung, M.M. Fadhali, R.A. Areshi, F.D. Tan. "Optical and Electrical Characteristics of Silicon Nanowires Prepared by Electroless Etching". Nanoscale Res. Lett. 2017. 12(1): 425-436.

12. G.-J. Zhang, Y. Ning. "Silicon Nanowire Biosensor and its Applications in Disease Diagnostics: A Review”. Anal. Chim. Acta 2012. 749: 1-15.

13. S.A.F Rahman, N.A. Yusof, U. Hashim, R. Hushiarian, et al. "Enhanced Sensing of Dengue Virus DNA Detection Using $\mathrm{O}_{2}$ Plasma Treated-Silicon Nanowire Based Electrical Biosensor". Anal. Chim. Acta. 2016. 942: 74-85.

14. X. Cao, L. Mu, M. Chen, G. She. "A Facile Fluorescent Sensor Based on Silicon Nanowires for Dithionite". Appl. Surf. Sci. 2018. 441: 388-393.

15. Y. Qin, D. Liu, T. Zhang, Z. Cui. "Ultrasensitive Silicon Nanowire Sensor Developed by a Special Ag Modification Process for Rapid $\mathrm{NH}_{3}$ Detection". ACS Appl. Mater. Interfaces 2017. 9(34): 28766-28773.

16. H. Wang, W. Jiang, Y. Wang, X. Lui, et al. "Catalase-Like and Peroxidase-Like Catalytic Activities of Silicon Nanowire Arrays". Langmuir 2013. 29(1): 3-7.

17. G. Cohn, R.A. Eichel, Y. Ein-Ali. "New Insight into the Discharge Mechanism of SiliconAir Batteries Using Electrochemical Impedance Spectroscopy". Phys. Chem. Chem. Phys. 2013. 15(9): 3256-3263.

18. A. Soam, N. Arya, A. Kumbhar, R. Dusane. "Controlling the Shell Microstructure in a LowTemperature-Grown SiNWs and Correlating it to the Performance of the SiNWs-Based Micro-Supercapacitor”. Appl. Nanosci. 2016. 6(8): 1159-1165.

19. J. Chen, T. Subramami, Y. Sun, W. Jevasuwan, et al. "Efficiency Enhancement of Silicon Nanowire Solar Cells by Using UV/Ozone Treatments and Micro-Grid Electrodes". Appl. Surf. Sci. 2018. 439: 1057-1064.

20. H. Gebavi, L. Mikak, M. Marcius, M. Sikic, et al. "Silicon Nanowires Substrates Fabrication for Ultra-Sensitive Surface Enhanced Raman Spectroscopy Sensors". Croat. Chem. Acta . 90(2): 259-262. 
DOI: $10.1177 / 0003702819881222$

21. F. Bai, M. Li, P. Fu, R. Li, et al. "Laser-Modified Black Titanium Oxide Nanospheres and Their Photocatalytic Activities Under Visible Light". APL Mater. 2015. 7(29): 1607016077.

22. M.-W. Shao, M.-L. Zhang, N.-B. Wong, D.D. Ma, et al. "Ag-Modified Silicon Nanowires Substrate for Ultrasensitive Surface-Enhanced Raman Spectroscopy”. Appl. Phys. Lett. 2008. 93(23): 233118-233121.

23. M.-L. Zhang, X. Fan, H.-W. Zhou, M.-W. Shao, et al. "A High-Efficiency Surface-Enhanced Raman Scattering Substrate Based on Silicon Nanowires Array Decorated with Silver Nanoparticles". J. Phys. Chem. C. 2010. 114(5): 1996-1975.

24. D.H. Doehlert. "Uniform Shell Design". Appl. Stat. 1970. 19(3): 231-239.

25. H. Pinkowska, E. Oliveros. "Application of the Doehlert Matrix for the Determination of the Optimal Conditions of Hydrolysis of Soybean Protein in Subcritical Water". Ind. Eng. Chem. Res. 2014. 53(4): 1320-1326.

26. A. Hannachi, S. Hammami, N. Raouafi, H. Maghraoui-Meherzi. "Preparation of Manganese Sulfide (MnS) Thin Films by Chemical Bath Deposition: Application of the Experimental Design Methodology”. J. Alloys Compd. 2016. 663: 507-515.

27. M. Bigan, B. Mutel. "Cold Remote Plasma Modification of Wood: Optimization Process Using Experimental Design”. Appl. Surf. Sci. 2018. 453: 423-435.

28. M.-L. Zhang, K.-Q. Peng, X. Fan, J.-S. Jie, et al. "Preparation of Large-Area Uniform Silicon Nanowires Arrays Through Metal-Assisted Chemical Etching”. J .Phys .Chem. 2008. 112(12): 4444-4450.

29. K. Liu, S. Qu, X. Zhang, F. Tan, Z. Wang. "Improved Photovoltaic Performance of Silicon Nanowire/Organic Hybrid Solar Cells by Incorporating Silver Nanoparticles". Nanoscale Res. Lett. 2013. 8: 88-94.

30. G.A. Lewis, D. Mathieu, R. Phan-Tan-Luu. Pharmaceutical Experimental Design. Boca Raton, FL: CRC Press, 1998.

31. H. Pinkowska, E. Oliveros. "Application of the Doehlert Matrix for the Determination of the Optimal Conditions of Hydrolysis of Soybean Protein in Subcritical Water" Ind. Eng. Chem. Res. 2014. 53(4): 1320-1326.

32. K. Uchinokura, T. Sekine, E. Matsuura. "Raman Scattering by Silicon". Solid State Commun. 1972. 11(1): 47-49. 
DOI: $10.1177 / 0003702819881222$

33. A. Sena, G. Junior, I. Barretto, S. Assis. "Application of Doehlert Experimental Design in the Optimization of Experimental Variables for the Pseudozyma sp. (CCMB 306) and Pseudozyma sp. (CCMB 300) Cell Lysis". J. Food Sci”. Technol. 2012. 32: 762-767.

34. P. Hildebrandt, M. Sockbinge. "Surface-Enhanced Resonance Raman Spectroscopy of Rhodamine 6G Adsorbed on Colloidal Silver" J. Phys. Chem. 1984. 88(24): 5935-5944.

35. J.A. Dieringer, K.L. Wustholz, D.J. Masiello, J.P. Camden, et al. "Surface-Enhanced Raman Excitation Spectroscopy of a Single Rhodamine 6G Molecule". J. Am. Chem. Soc. 2009. 131(2): 849-854.

36. D. Mathieu, J. Nony, R. Phan-Tan-Luu. "New Efficient Methodology for Research Using Optimal Design (NEMROD) Software”. Marseille, France: LPRAI, 2000.

37. L.T.Q. Ngan, D.T. Cao. "Improvement of Raman Enhancement Factor Due to the Use of Silver Nanoparticles Coated Obliquely Aligned Silicon Nanowire Arrays in SERS Measurements”. Int. J. Nanotechnol. 2015. 12: 358-366.

\section{Captions}

Figure 1. Graphical representation of the Doehlert experiments.

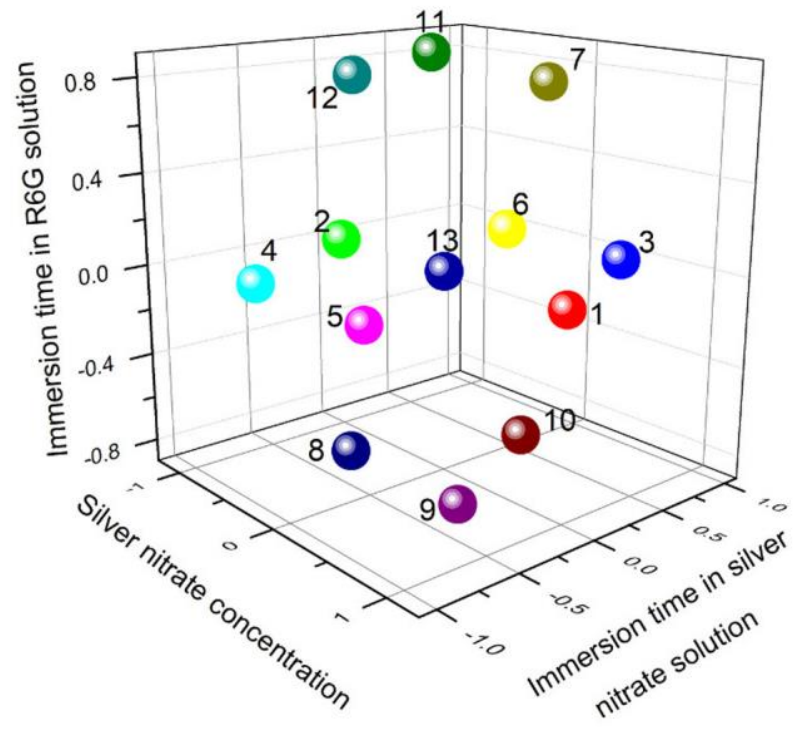


Figure 2. Results obtained using SEM: (a) Cross-sectional SEM image of SiNWs; (b) surface SEM image of AgNPs/SiNWs.
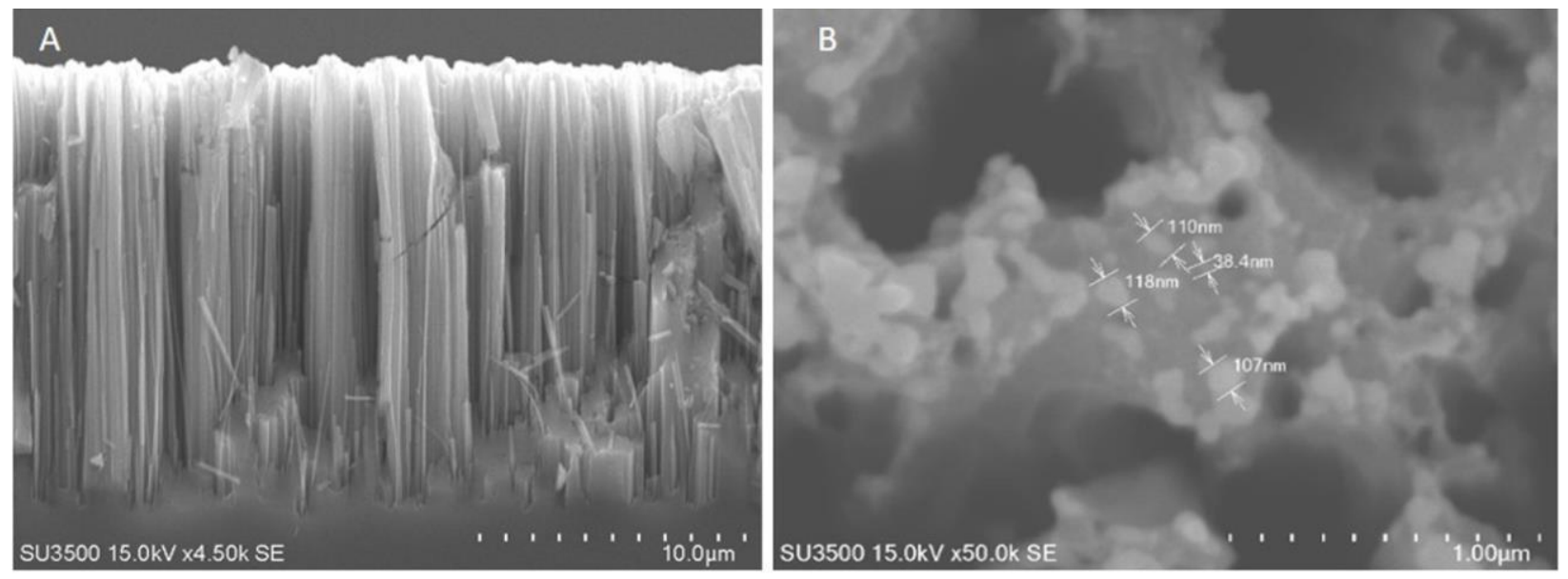

Figure 3. Raman spectra of SiNWs (a) ; R6G $\left(10^{-6} \mathrm{M}\right) / \mathrm{SiNWs}$ (b) and R6G $\left(10^{-6}\right.$ M)/AgNPs/SiNWs (c) for an excitation at $632.8 \mathrm{~nm} ; \mathrm{L}_{1}, \mathrm{~L}_{2}, \mathrm{~L}_{3}$ and $\mathrm{L}_{4}$ peaks correspond to the peaks of the main $\mathrm{R} 6 \mathrm{G}$ vibration modes, $\mathrm{L}_{\mathrm{Si}}$ corresponds to a $\mathrm{Si}$ vibrational mode. The insert represents a zoom of the spectra $a$ and $b$ in the range $1200-1800 \mathrm{~cm}^{-1}$.

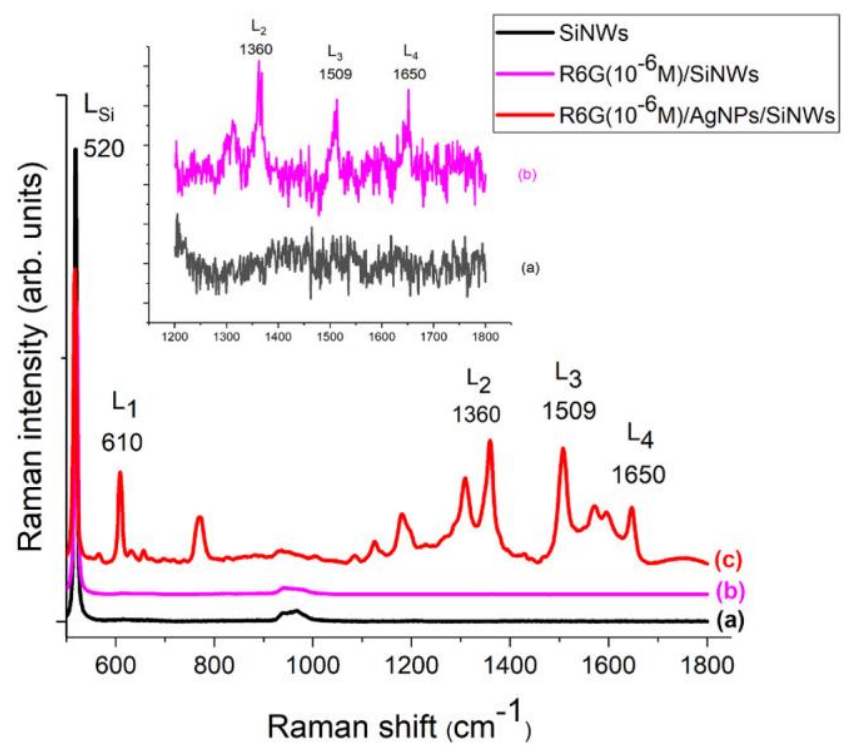

Figure 4. SERS spectra of R6G $\left(10^{-6} \mathrm{M}\right) / \mathrm{AgNPs} / \mathrm{SiNW}$ s with two excitation wavelengths $488 \mathrm{~nm}$ and $632.8 \mathrm{~nm}$. 
DOI: $10.1177 / 0003702819881222$

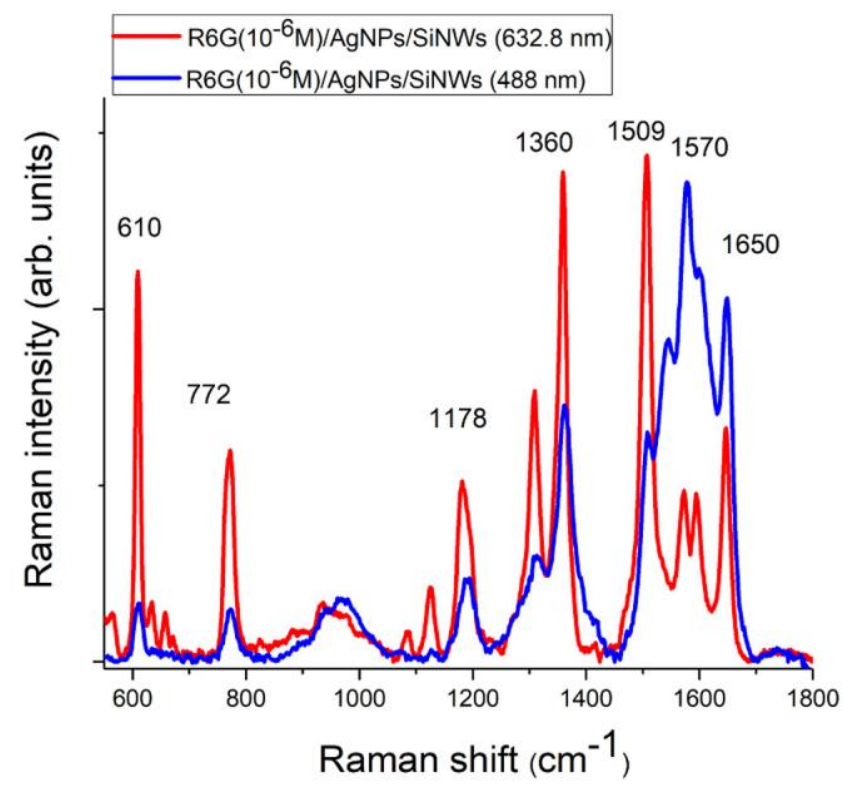

Figure 5. Evolution of normalized intensity of selected modes from R6G of the fifteen experiments prepared according the experimental design.

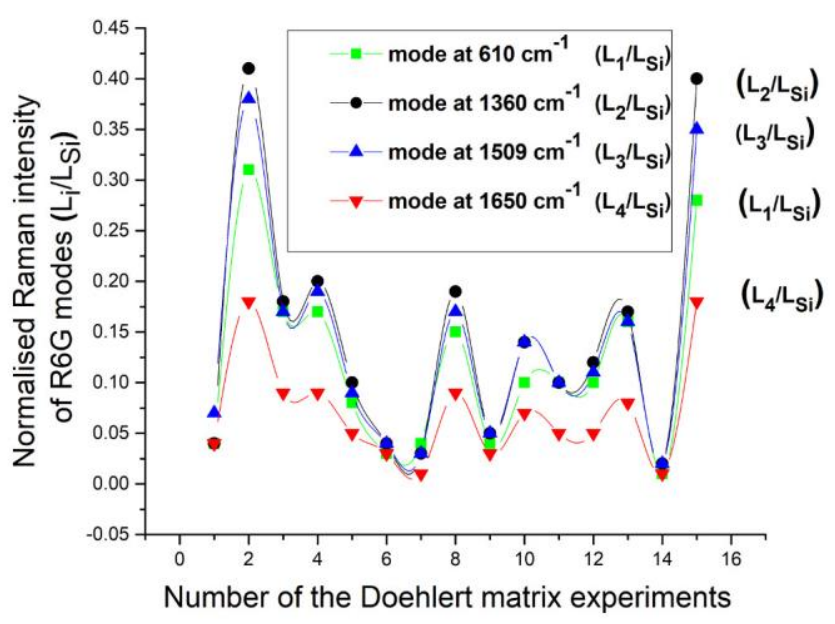

Figure 6. Graphical analysis of effects on the experimental response. $b_{i}$ coefficients represent the estimation of the main effects of $U_{i}$; $b_{i i}$ coefficients represent the estimation of the second order effects of $U_{i} ; b_{i j}$ coefficients represent the interactions between $U_{i}$ and $U_{j}$. 
DOI: $10.1177 / 0003702819881222$

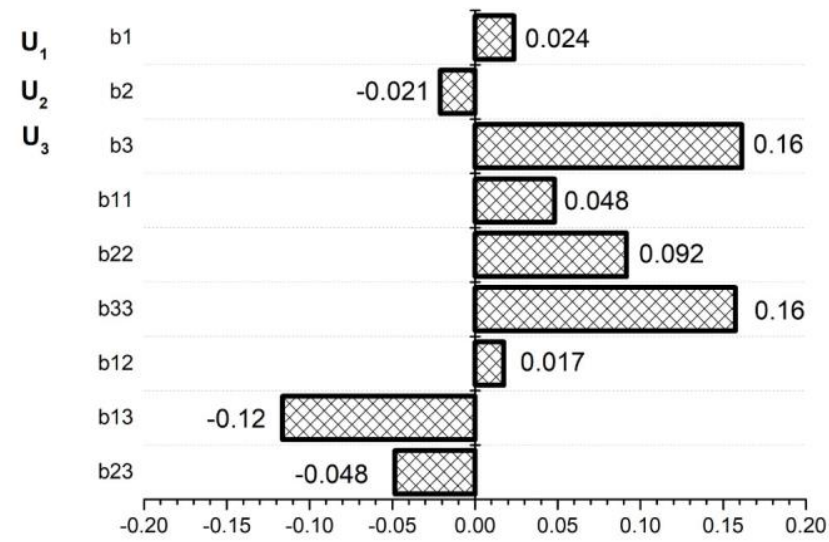


Figure 7. Results obtained using the Doehlert matrix: (a) Contour plots of SERS responses with respect to silver nitrate time (seconds) and R6G time (minutes) at a fixed silver nitrate concentration $5 \mathrm{mM}$; (b) three-dimensional corresponding plot; (c) contour plots of SERS responses versus silver nitrate concentration (M) and R6G time (minutes) at a fixed silver nitrate time 67.5 seconds; (d) three-dimensional corresponding plot; (e) contour plots of SERS responses with respect to silver nitrate time (seconds) and silver nitrate concentration (M) at a fixed R6G time 38 minutes and F) three-dimensional corresponding plot.

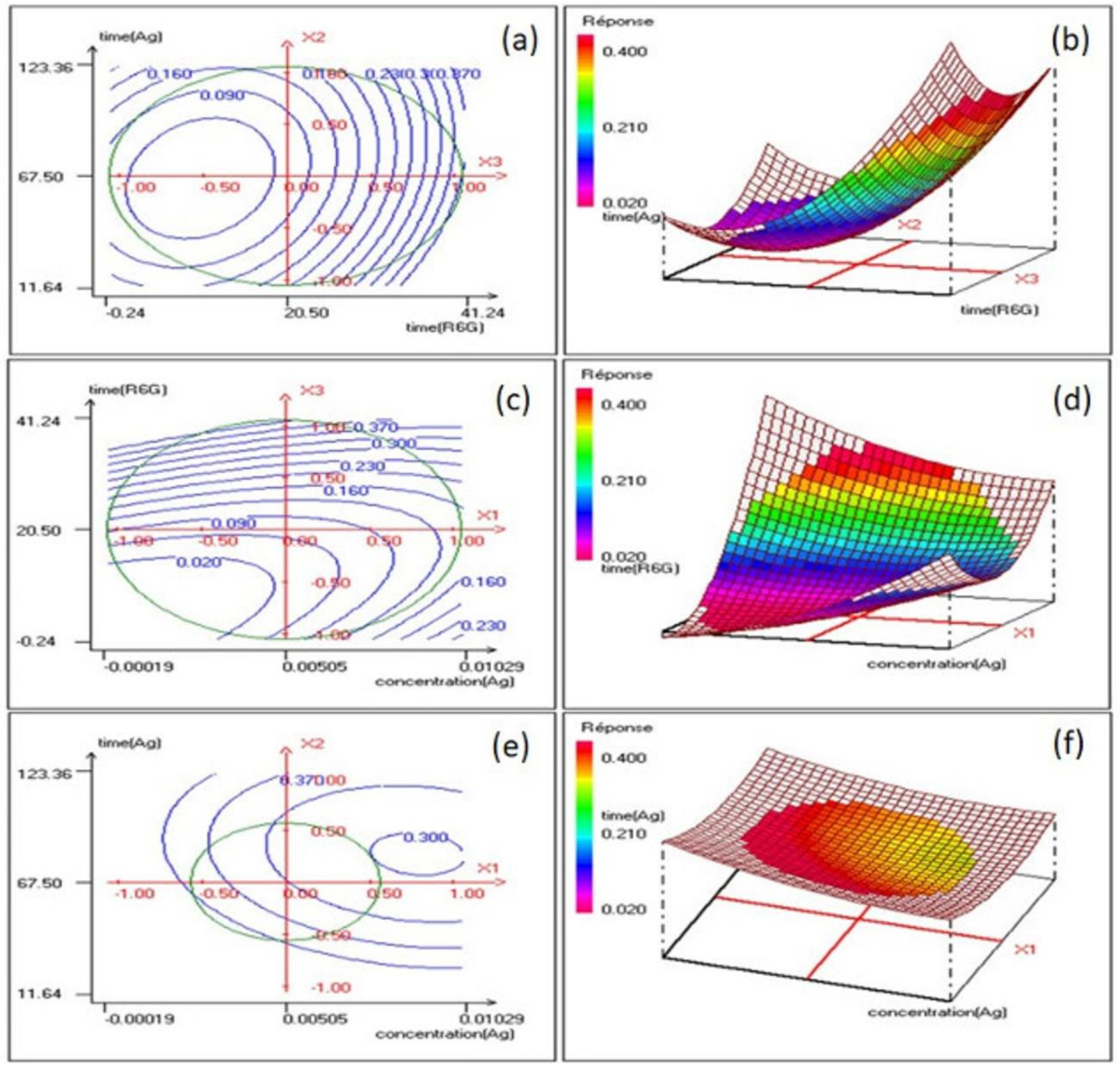


DOI: $10.1177 / 0003702819881222$

Figure 8. SERS spectra of AgNPs/SiNWs (a) and R6G/AgNPs/SiNWs for different R6G concentrations ranging from (b) $10^{-11} \mathrm{M}$, (c) $10^{-10} \mathrm{M}$, (d) $10^{-8} \mathrm{M}$ to (e) $10^{-6} \mathrm{M}$ for an excitation at $632.8 \mathrm{~nm}$.

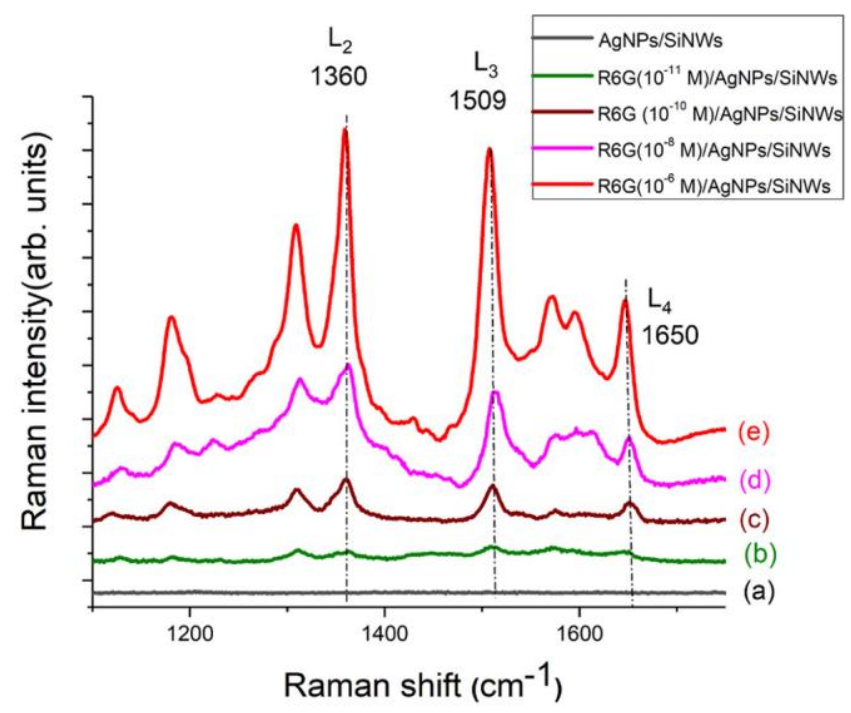

Tables

Table I. Doehlert experimental matrix.

\begin{tabular}{|l|l|l|l|l|l|l|l|}
\hline \multicolumn{2}{|l|}{$\begin{array}{l}\text { Experiment } \\
\text { number }\end{array}$} & \multicolumn{3}{l|}{ Coded variables } & \multicolumn{3}{l|}{ Real variables } \\
\hline $\begin{array}{l}\text { Before } \\
\text { rand }\end{array}$ & $\begin{array}{l}\text { After } \\
\text { rand }\end{array}$ & $\mathbf{X}_{1}$ & $\mathbf{X}_{\mathbf{2}}$ & $\mathbf{X}_{\mathbf{3}}$ & $\mathbf{U}_{1}$ & $\mathbf{U}_{\mathbf{2}}$ & $\mathbf{U}_{\mathbf{3}}$ \\
\hline 1 & 4 & 1.0000 & 0.0000 & 0.0000 & 0.01000 & 67.50 & 20.50 \\
\hline 2 & 7 & -1.0000 & 0.0000 & 0.0000 & 0.00010 & 67.50 & 20.50 \\
\hline 3 & 8 & 0.5000 & 0.8660 & 0.0000 & 0.00753 & 113.18 & 20.50 \\
\hline 4 & 12 & -0.5000 & -0.8660 & 0.0000 & 0.00258 & 21.82 & 20.50 \\
\hline 5 & 3 & 0.5000 & -0.8660 & 0.0000 & 0.00753 & 21.82 & 20.50 \\
\hline 6 & 11 & -0.5000 & 0.8660 & 0.0000 & 0.00258 & 113.18 & 20.5 \\
\hline 7 & 13 & 0.5000 & 0.2887 & 0.8165 & 0.00753 & 82.73 & 36.49 \\
\hline 8 & 5 & -0.5000 & -0.2887 & -0.8165 & 0.00258 & 52.27 & 4.51 \\
\hline 9 & 1 & 0.5000 & -0.2887 & -0.8165 & 0.00753 & 52.27 & 4.51 \\
\hline 10 & 9 & 0.0000 & 0.5778 & -0.8165 & 0.00505 & 97.96 & 4.51 \\
\hline
\end{tabular}


DOI: $10.1177 / 0003702819881222$

\begin{tabular}{|l|l|l|l|l|l|l|l|}
\hline 11 & 2 & -0.5000 & 0.2887 & 0.8165 & 0.00258 & 82.73 & 36.49 \\
\hline 12 & 15 & 0.0000 & -0.5778 & 0.8165 & 0.00505 & 37.04 & 36.49 \\
\hline 13 & 10 & 0.0000 & 0.0000 & 0.0000 & 0.00505 & 67.50 & 20.50 \\
\hline 14 & 6 & 0.0000 & 0.0000 & 0.0000 & 0.00505 & 67.50 & 20.50 \\
\hline 15 & 14 & 0.0000 & 0.0000 & 0.0000 & 0.00505 & 67.50 & 20.50 \\
\hline
\end{tabular}

Table II. The experimental field.

\begin{tabular}{|l|l|l|l|l|}
\hline & Factor Ui & Unit & Center $\left(\mathbf{U}_{\mathbf{i} 0}\right)$ & $\begin{array}{l}\text { the range of } \\
\text { variation }\left(\Delta \mathbf{u}_{\mathbf{i}}\right)\end{array}$ \\
\hline $\mathrm{U}_{1}$ & Silver nitrate concentration & $\mathrm{M}$ & 0.00505 & 0.00495 \\
\hline $\mathrm{U}_{2}$ & Silver nitrate time & Second & 67.50 & 52.72 \\
\hline $\mathrm{U}_{3}$ & R6G time & Minute & 20.50 & 19.58 \\
\hline
\end{tabular}

